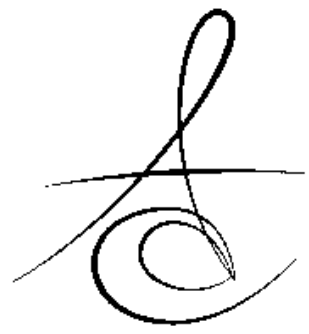

\title{
MAKSİLLER SİNÜS MALİGN NEOPLAZMLI HASTANIN PROTETİK REHABİLİTASYONU: OLGU SUNUMU ${ }^{*}$
}

\section{PROSTHETIC REHABILITATION OF A PATIENT WITH MAXILLARY SINUS NEOPLASM: A CASE REPORT ${ }^{\neq}$}

\author{
Dr. Öğr. Üyesi Hatice ÖZDEMİR*
}

\author{
Öğr. Gör. Merve KöSEOĞLU**
}

\begin{abstract}
Makale Kodu/Article code: 2984
Makale Gönderilme tarihi: 02.08.2016

Kabul Tarihi: $\quad 27.09 .2016$
\end{abstract}

\section{öz}

Benign ve malign neoplazmların, maksiller kistlerin, travmatik ve konjenital malformasyonların cerrahi tedavisi maksiller defektlere neden olmaktadır. Maksiller defektler, oronasal ve oroantral bağlantılara ve bunun sonucunda yenilen besinlerin ve gıdaların burundan geri akışına ve hipernazal konuşmaya neden olmaktadır. Hastaların obtüratörlerle protetik rehabilitasyonu ile estetik, fonksiyonel, sosyal ve psikolojik problemlerinin çözümü amaçlanmaktadır. Defektin büyüklüğü ve lokalizasyonu, mevcut yumuşak doku undercutları, destek dişlerin sayısı ve kemik desteği obtüratörün dizaynını etkilemektedir. Obtüratörün retansiyonu ve stabilizasyonu oral fonksiyonları geliştirmektedir. Bu vakada, maksiller sinüs malign neoplazmı teşhisi konulmuş 17 yaşında bayan hasta kliniğimize başvurmuştur. Maksiller anterior bölgenin rezeksiyonu, ilgili dişlerin çekimi, radyoterapi uygulaması ardından nazogastrik sonda yerleştirilmiştir. Radyoterapiden 1 ay sonra, hastanın radyoterapisti beslenmenin oral yoldan sağlanması için nazogastrik sondanın çıkarılması ve hastanın protezle rehabilite edilmesini istemiştir. Metal alt yapılı obtüratör protezin tutuculuğu konvansiyonel obtüratör protezlerden daha fazla olduğu için metal altyapılı geçici obtüratör protez uygulanmıştır. Kontrol randevularında obtüratör protezlerde herhangi bir estetik ve fonksiyonel problem görülmemiştir.

Anahtar Kelimeler: Maksiller sinüs karsinomu, Maksiller Defekt, Obturatör, Hollow bulb, Protetik Rehabilitasyon

\begin{abstract}
Surgical treatment of benign or malignant neoplasms, maxillary cysts, traumatic and

congenital malformations induce maxillary defects. Maxillary defects create oronasal and oroantral communications that lead to nasal regurgitation of food and liquids and hyper-nasal peech. Prosthodontic rehabilitation of patients with obturators aims to solve the patients' aesthetic, functional, social and psychological problems. Location and size of the defects, vailable soft tissue undercuts, the number and bone support of the remaining abutment teeth effect the design of obturators. Retention and stability of the obturators improve oral functions. In this case the patient was a 17 years old girl. She was diagnosed with maxillary sinus malignant neoplasm. After the resection of maxillary anterior region, extraction of several teethand undergoing radiotherapy, a nasogastric tube was placed. One month after radiotherapy, patient's radiotherapist aimed to remove the nasogastric tube and help her with feeding so wanted us to rehabilitate the patient with a prosthetis. A temporary obturator prosthesis with metal framework was designed. Because the retention of obturator prosthesis with metal framework is better than conventional obturator prosthesis. At the recall visits obturator prosthesis hasn't got any aesthetic or functional problems.

Key Words: Maxillary sinus carcinoma, Maxillary defect, Obturator, Hollow bulb, Prosthetic rehabilitation
\end{abstract}

* Atatürk Üniversitesi, Diş Hekimliği Fakültesi, Protetik Diş Tedavisi AD, Erzurum.

** Sakarya Üniversitesi, Diş Hekimliği Fakültesi, Protetik Diş Tedavisi AD, Sakarya.

₹Bu çalışma 5. Uluslarası Türk Prostodonti ve İmplantoloji Derneği(TPID) Palandöken Kış

Sempozyumu (18-20 Mart 2016 Erzurum, Türkiye)'nda poster olarak sunulmuştur. 


\section{GİRİş}

Onkolojik cerrahi sonucunda hastalarda fasiyel deformite ve asimetri, diş kaybı, maksiller ve mandibular çene kemiklerinde parsiyel/ total kemik kaybı görülmektedir. ${ }^{1}$ Onkoloji hastalarında rekonstrüksiyon cerrahi flep uygulamaları, protetik obtüratör uygulamaları veya cerrahi ve protetik uygulamaların kombinasyonuyla yapılmaktadır. ${ }^{2-4}$ Defektin büyüklüğü, anatomisi ve geometrisi, rezidüel kemik miktarı, yumuşak doku desteği, dentisyonun durumu ve hastanın genel sağlığı tedavi seçeneklerini belirlemede etkilidir. ${ }^{3-7}$ Belirli yükseklikte vertikal defektle birlikte oroantral fistülün olduğu ve yumuşak damağın etkilenmediği tek taraflı maksiller defektlerin rekonstrüksiyonunda obtüratörler tatmin edici sonuçlar vermektedirler. ${ }^{8-13}$ Obtüratörlerin retansiyonu, tutucuların kullanımı, defektin sınırlarıyla birebir uyumlu protez yapımı ve implant uygulamalarıyla arttırımaktadır. ${ }^{14-16}$ Obtüratör uygulamasıyla maksiller defektlerin restorasyonu, estetiğin düzenlenmesi, azalmış çiğneme ve yutkunma fonksiyonlarının arttıııması, nazal sıvı akışının ve hipernazal konuşmanın önlenmesi amaçlanmaktadır. ${ }^{3,17}$

Kalıcı obtüratörler, üst çene rezeksiyonundan 13 hafta sonra tek parça veya çok parça halinde uygulanan, üst yapı ve alt yapıdan oluşan protez tipleridir. $^{2,8}$ Obtüratör protezlerin üst yapısı retansiyon ve stabiliteyi arttırmak için defekt bölgesinde tam bir kapama sağlamalıdır. ${ }^{18,19}$ Ancak bu durumda protezlerin ağırlığı artacak ve yer çekimi kuvveti karşısında protez yerinden çıkacaktır. ${ }^{18}$ Protezin ağırığını azaltmak amacıyla hasta tarafindan kolaylıkla tolere edilebilen açık ve kapalı boşluklu obtüratörler dizayn edilmiştir. ${ }^{20-}$

${ }^{22}$ Açık boşluklu obtüratörlerde gıda ve mukus birikimi olduğundan hasta tarafından sıklıkla temizlenmesi gerekmekte ya da birikimi önlemek için proteze delik açılması gerekmektedir. ${ }^{23}$ Kapalı boşluklu obtüratörlerde ise gıda ve mukus birikimi olmamaktadır bu da hasta konforunu arttırmaktadır. ${ }^{24}$

Kapalı boşluklu obtüratörlerde ağırlığı azaltmak için farklı metodlarla, ışıkla sertleşen rezin, kendiliğinden sertleşen akrilik rezin ve silikon bazı materyaller kullanımaktadır. ${ }^{25,26}$ Silikon bazlı materyaller spesifik klinik durumlarda kullanılabilen materyaller olmalarına karşın, poröz olmaları, uzun dönem stabilitelerinin az olması ve rutin periyodik kontrollerle değiştirilmeye gereksinim duyması gibi dezavantajlara sahiptir. ${ }^{21,27}$ Isıyla sertleşen akrilik rezin ise sağlam ve biouyumlu olma gibi avantajlara sahip bir maddedir. ${ }^{28}$
$\mathrm{Bu}$ olgu sunumunda kliniğimize başvuran 17 yaşındaki kısmi maksillektomi yapılmış hastaya uygulanan protetik tedavi sunulacaktır.

\section{OLGU SUNUMU}

Atatürk Üniversitesi Diş Hekimliği Fakültesi Protetik Diş Tedavisi Anabilim Dalı kliniğine başvuran kısmi maksillektomi yapılmış 17 yaşındaki bayan hastanın anamnezinde maksiller sinüs malign neoplazmı tanısıyla operasyon geçirdiği öğrenildi. Ağız içi muayenede, hastanın üst çenesinde sağ 1 . ve 2 . büyük azı dişleri ile sol tarafta da kanin dişi ile premolar ve molar dişlerinin olduğu ve alt çenesinde tüm dişlerinin olduğu görüldü (Şekil 1).

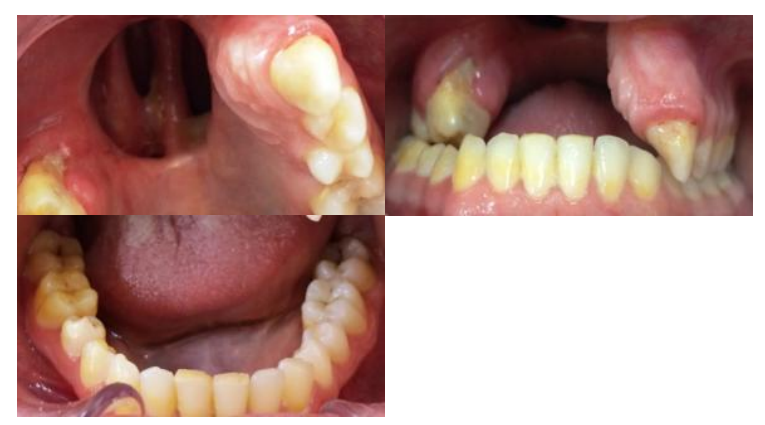

Şekil 1. Defekt bölgesinin ve alt çenenin ağız içi görüntüleri

Ağız dışı muayenede, üst dudağın defekt bölgesine doğru hafif çökük olduğu görüldü. Hasta, operasyon sonrası rahat beslenebilmesi için takılan nazogastrik sondadan beslendiğini ve bu durumdan çok rahatsız olduğunu belirtti. Operasyonunu gerçekleştiren cerrahi uzmanından konsültasyon istendi. Cerrah, hastanın radyoterapi görmesi gerektiğini ve protez işlemlerine de radyoterapiden 3 ay sonra başlanabileceğini belirtti. Hasta, edinilen bilgi doğrultusunda motive edildikten sonra gönderildi. Radyoterapi sürecinden sonra bu defa da radyoterapi uzmanından konsültasyon istendi. Radyoterapi uzmanının da onayıyla hastanın protez işlemlerine başlandı. Protez işlemleri sonlanana kadar hastanın sondası çıkarttırımadı.

İlk seansta, hastanın ağzına uygun büyüklükteki metal hazır kaşıklarla irreversible hidrokolloid (Zhermack Hydrogum5 High Stability Alginate Impression Material, İtalya) maddesiyle birinci ölçü alındı. Üst çeneden ölçü alınırken ölçü maddesinin defekt bölgesindeki boşluklara kaçmaması için önce vazelinli gazı bezle kapatıldı. Ölçülere beyaz alçı

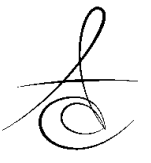


dökülerek modeller elde edildi. Üst çene modeli üzerine basplaktan (Imicryl Imibase Dental Baseplates, Türkiye) özel ölçü kaşığı hazırlandı. İkinci seansta, özel ölçü kaşığı hasta ağzında kontrol edilerek kenar uyumları değerlendirildi. Dudak vestibül bölgesindeki sulkus çok sığ olduğu için bu bölge çok az yardımcı mum (Kerr Utility Wax Rods Round, Almanya) ile uzatılarak kaşık hasta ağzında kontrol edildi. Aynen ilk ölçüde olduğu gibi yine vazelinli gazlı bezle defekt bölgesi kapatıldıktan sonra irreversible hidrokolloid ölçü maddesiyle ikinci ölçü alındı. Hidrokolloid ölçü maddesi kullanılmasındaki amaç, defekt bölgesindeki andırkatlı bölgelerin, detaylı bir şekilde ölçüsünün alınabilmesidir. Alınan ölçüye sert alçı (Denstone 3 Dental Model Stone Type 3, Türkiye) dökülerek obturatör yapılacak ana model elde edildi. Hastanın kısmi dişsizlik durumu, yaşı ve diş boylarının kısalığı göz önünde bulundurularak iskelet alt yapılı parsiyel protez şeklinde obturatör yapımına karar verildi. Bükme kroşe yeterli bir retansiyon ve tutuculuk sağlayamayacağı için metal iskelet bünyesinde hazırlanan döküm kroşelerle maksimum retansiyon ve tutuculuk elde edilmesi amaçlandı. Ana model iskelet planlaması yapıldıktan sonra diş laboratuvarına gönderildi. Sonraki seansta laboratuvardan gelen metal iskelet hasta ağzında kontrol edildi (Şekil 2).

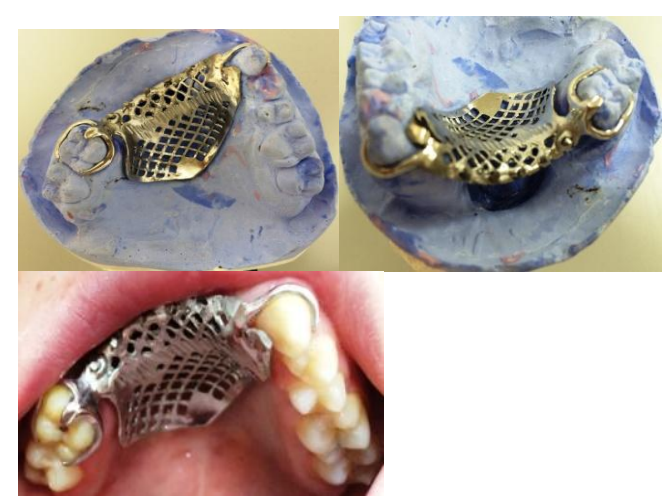

Şekil 2. Metal iskeletin model üzerinde ve ağız içi görüntüleri

Uyumu iyi olan metal iskeletle hastanın dişlerinin kapanışı alındı. Diş rengi ve boyutu seçilip, alt ve üst modeller birbirine sabitlenerek laboratuvara iletildi. Dişler dizildikten sonra ağızda provası yapıldı. Kapanış ve estetiğinde hiçbir sorun görülmeyen protez bitim işlemleri için laboratuvara iletildi (Şekil 3). Hastaya bir sonraki provaya gelmeden önce sondasını çıkarttırabileceği söylendi.

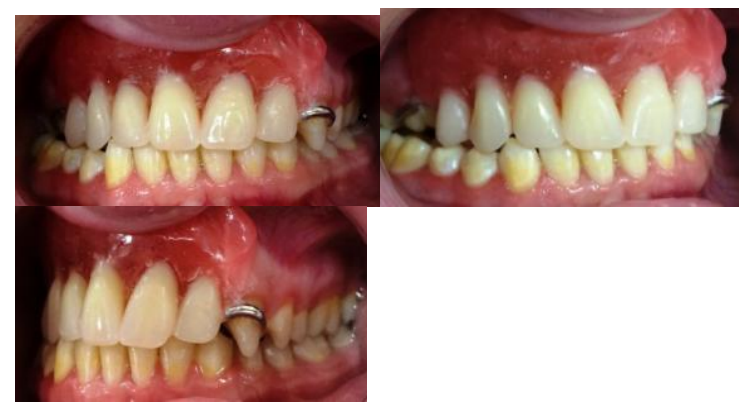

Şekil 3. Dişli provanın ağız içi görüntüleri

Obturatörün bulb kısmının yumuşak astar maddesinden olması planlandığı için öncelikle bu kısma ısıyla polimerize olan yumuşak astar maddesi yerleştirilip (Detax Molloplast B Silicone Based Soft Denture Liner, Almanya) sınırları kontrol edildi. Tüm andırkatlı bölgelerin yumuşak astar maddesiyle kapandığı gözlendikten sonra, diğer kısımlara sıcak akrilik (Imicryl IQ- 15 S Diş Kaide Malzemesi, Türkiye) tepilerek rutin protez bitim işlemlerine devam edildi ve metal iskelet alt yapısı olan yumuşak bulblu obturatör bitirildi (Şekil 4).

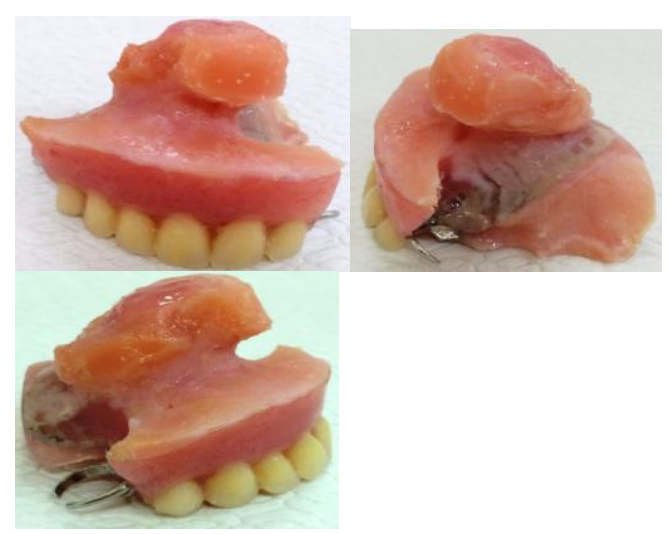

Şekil 4. Protezin bitim safhasının ağız dışı görüntüleri

Tesviye ve cila işlemlerinden sonra hasta ağzına takılarak kontrol edildi. Hem metal iskelet bünyesindeki kroşeler hem de andırkatlı bölgelere yerleştirilen yumuşak astar maddesinden dolayı obturatörde maksimum retansiyon ve tutuculuk sağlanmış oldu. Hasta sondadan kurtulduğu için genç yaşına rağmen hareketli protezi çok çabuk kabullendi (Şekil 5).

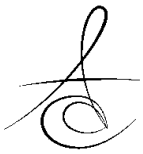




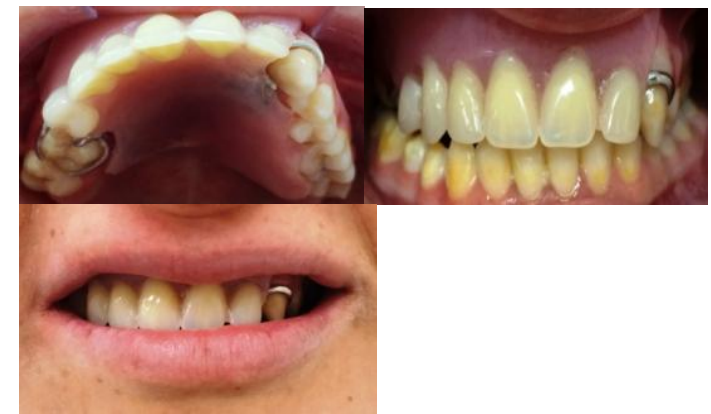

Şekil 5. Protezin bitim safhasının ağız içi ve ağız dışı görüntüleri

1 hafta sonraki kontrolde hasta protezinin tutuculuğunun gayet iyi olduğunu ve protezinin estetiğiyle ilgili olarak çevresinden olumlu tepkiler aldığını dile getirdi. Hasta 6 ay sonra tekrar kontrole çağrılarak obturatörünün yumuşak astar kısmı yenilendi. Bu süreçte hastanın normal kilosuna ulaştığı da gözlemlendi (Şekil 6).

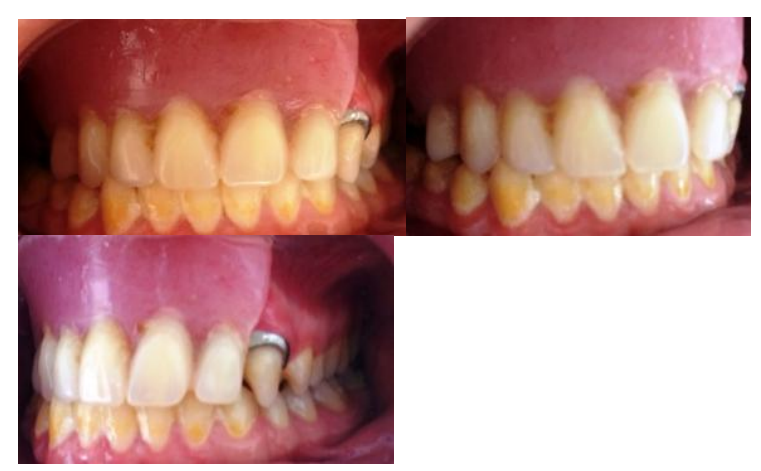

Şekil 6.6 ay sonraki kontrolde protezin ağız içi görünümü

\section{TARTIŞMA}

Kalıcı obtüratörler üst çene rezeksiyonundan 13 hafta sonra uygulanabilirler ${ }^{2,8}$. Kalıcı obtüratörlerin uygulanma zamanı, defektin büyüklüğüne, tümörün tedavi süreci ve prognozuna, var olan obtüratörün etkinliğine bağlı olarak değişiklik göstermektedir ${ }^{14}$. Bu vakada radyoterapi uzmanının onayıyla radyoterapiden 3 ay sonra protez işlemlerine başlanmıştır.

Kapalı boşluklu obtüratörlerin dizaynıyla protezin ağırlığı azaltılarak retansiyon arttırımış, fizyolojik fonksiyonlar iyileştirilerek çevre dokulara iletilen stres azaltılmış böylece yutkunma kolaylaşmış ve çevre dokuların rejenerasyon yeteneği arttırılmıştır. Ayrıca kapalı boşluklu obtüratör dizaynıyla protezin ağırlığı azaltıldığından protezin hasta tarafından kabul edilebilirliği artmıştır. Protezin ağırığının azaltılmasıyla kas dengesinde fizyolojik değişiklikler ve ileri derecede atrofi görülmemiştir ${ }^{29-33}$. Bu vakada yumuşak astar ile bulb şekillendirilmesi yapılarak protezin ağırlığının azaltılması ve fizyolojik fonksiyonların iyileştirilmesi amaçlanmıştır.

Obtüratör protezlerin tutuculuğunda dişler önemli yere sahiptirler. Hastada mevcut dişlerin pozisyonu, sayısı ve periodontal sağlı̆ı protezin tutuculuğunu etkilemektedir. Defekt sahası büyükse ve mevcut dişlerin bir kısmı veya tamamı stabil değilse ekstrakronal tutucu kullanımı gerekmektedir. Alveolar kemiğin şekli ve büyüklüğü de protezin retansiyonunu etkilemektedir. Protezin defektin olduğu nazal/ paranazal kaviteye uzanmasıyla dikey ve yatay yer değiştirmelere karşı direnç sağlanması amaçlanmıştır. Protezin yüksek yapılan lateral duvarları indirekt tutucu olarak kulanılabilir $^{32}$. Bu vakada defekte komşu kanin ve 1. molar dişe konulan kroşeler ve protezin defekt bölgesine uzanan yüksek lateral duvarları ile tutuculuk ve direnç sağlanmıştır.

Protezin sınırlarının mukobukkal katlantıya, protezin obtüratör kısmının ise defektin tüm yan duvarlarına maksimum derecede uzanmasıyla protezin stabilizasyonu arttırılabilir. Ayrıca oklüzal kuvvetlerin çenelerin sentrik ve eksentrik tüm pozisyonlarında maksimum derecede dağılması ve prematür kontakların elimine edilmesiyle lateral kuvvetlerden kaynaklı stres azaltılacak ve protezin stabilizasyonu arttırılacaktır ${ }^{34}$. Bu vakada protezin obtüratör kısmı defekt bölgesine maksimum derecede uzatılmış, oklüzyon kontrol edilerek prematür kontaklar elimine edilmiş ve tüm pozisyonlarda oklüzal yükün eşit derecede dağılmasına dikkat edilmiştir. Böylece protezin stabilizasyonu arttırılmıştır.

Sağlam olan destek dişlere yerleştirilen tırnaklar, alveolar kemiğin yüksekliği ve şekli, sulkus derinliği, protezin defekt bölgesine uzanan kısımları protezin desteğinin sağlanmasında etkilidir. Eğer defekt orta hattı kapsıyorsa nasal septumdan destek alınabilir $^{14}$. Bu vakada kanin ve 1.molar dişlere yerleştirilen tırnaklar, labial sulkusa uzanan protez kenarları, defekt bölgesine uzanan protezin bulb kısmı ve nasal septum yardımıyla protezin desteği sağlanmıştır.

Obtüratör yapımında farklı malzemeler kullanılmaktadır. Akrilik rezin obtüratör yapımında sıkça kullanılan bir malzeme olmasına karşın tüm

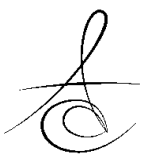


gereksinimleri karşılamamaktadır ${ }^{35,36}$. Obtüratör yapımında daha iyi retansiyon ve daha az irritasyon sağlamak, protezin ağırlığını azaltmak ve protezin takıp çıkartıımasını kolaylaştırmak için sert akrilik yerine esnek silikon esaslı materyallerin kullanımı önerilmiştir $^{37,38}$. Buna bağlı olarak, hasta protezini rahatlıkla çıkarıp, yıkadıktan sonra kolayca takabilir; böylece protezin bakım ve temizliği daha kolay yapılabilir ${ }^{39}$.Bu vakada obtüratörün bulb kısmı yumuşak astar maddesinden yapılarak andırkatlı bölgeler yumuşak astarla kapatılmıştır. Ancak silikon esaslı yumuşak astar materyallerinin akrilik kaideye bağlanma oranı, akrilik esaslı yumuşak astar materyallerinden daha azdır bu nedenle belirli periodlarla silikon esaslı yumuşak astar materyallerinin değişimi gerekmektedir ${ }^{40}$. İyileşme ve yeniden şekillenmeye bağlı olarak ilk 1 yıl içerisinde protezin sınırlarında değişmeler olacaktır ${ }^{14,41}$. Bu vakada, protezin sınırlarındaki değişmeden ve silikon esaslı yumuşak astar materyalinin zamanla akrilik kaide ile bağlantısının zayıflamasından dolayı hastanın protez bitiminden 6 ay sonraki randevusunda yumuşak astar materyali yenilenmiştir.

Hatice Özdemir: ORCID ID: 0000-0001-8512-0471 Merve Köseoğlu: ORCID ID: 0000-0001-9110-9586

\section{KAYNAKLAR}

1. Hanawa S, Kitaoka A, Koyama S, Sasaki K. Influence of Maxillary Obturator Prostheses on Facial Morphology in Patients with Unilateral Maxillary Defects. J Prosthet Dent 2015;113:62-70.

2. Devlin H, Barker GR. Prosthetic Rehabilitation of The Edentulous Patient Requiring a Partial Maxillectomy. J Prosthet Dent 1992;67:223-7.

3. Brown JS, Shaw RJ. Reconstruction of The Maxilla and Midface: Introducing a New Classification. Lancet Oncol 2010;11:1001-8.

4. Nguyen CT, Driscoll CF, Coletti DP. Reconstruction of a Maxillectomy Patient with an Osteocutaneous Flap and Implant-retained Fixed Dental Prosthesis: A Clinical Report. J Prosthet Dent 2011;105:292-5.

5. Sharma AB, Beumer J . Reconstruction of Maxillary Defects: The Case for Prosthetic Rehabilitation. J Oral Maxillofac Surg 2005;63:1770-3.

6. Marx RE. Reconstruction of Defects Caused by Bisphosphonate-induced Osteonecrosis of The Jaws. J Oral Maxillofac Surg 2009;67:107-19.
7. Ruggiero SL, Dodson TB, Fantasia J, Goodday R, Aghaloo T, Mehrotra B.American Association of Oral and Maxillofacial Surgeons Position Paper on Medication-related Osteonecrosis of The Jaw 2014 update. J Oral Maxillofac Surg 2014;72:1938-56.

8. Eckhardt A, Telzrow T, Schulze A, Hoppe M, Kuettner $C$. Nasalance in Patients with Maxillary Defects: Reconstruction Versus Obturation. J Craniomaxillofac Surg 2007;35:241-5.

9. Rieger JM, Tang JA, Wolfaardt J, Harris J, Seikaly $\mathrm{H}$. Comparison of Speech and Aesthetic Outcomes in Patients with Maxillary Reconstruction Versus Maxillary Obturators After Maxillectomy. J Otolaryngol Head Neck Surg 2011;40:40-7.

10.Irish J, Sandhu N, Simpson C,Wood R, Gilbert R, Gullane P, Brown D, Golstein D, Devins G, Barker E. Quality of Life in Patients with Maxillectomy Prostheses. Head Neck. 2009;31:813-21.

11. Kornblith AB, Zlotolow IM, Gooen J, Huryn JM, Lerner T, Strong EW, Shah JP, Spiro RH, Holland JC. Quality of Life of Maxillectomy Patients Using an Obturator Prosthesis. Head Neck 1996;18:32334

12. Aramany MA. Basic Principles of Obturator Design for Partially Edentulous Patients. Part I: Classification.J Prosthet Dent 2001;86:559-61.

13. Ono $T$, Kohda $H$, Hori K, Nokubi T. Masticatory Performance in Postmaxillectomy Patients with Edentulous Maxillae Fitted with Obturator Prostheses.Int J Prosthodont 2007;20:145-50.

14. Keyf F. Obturator Prostheses for Hemimaxillectomy Patients. J Oral Rehabilitation 2001;28:821-9.

15. Roumanas ED, Nishimura RD, Davis BK, Beumer J III. Clinical Evaluation of Implants Retaining Edentulous Maxillary Obturator Prostheses. J Prosthet Dent 1997;77:184-90

16. Yip JK, Borrell LN, Cho SC, Francisco H, Tarnow DP. Association Between Oral Bisphosphonate Use and Dental Implant Failure Among Middle-aged Women. J Clin Periodontol 2012;39:408-14.

17. Chigurupati R, Aloor N, Salas R, Schmidt BL. Quality of Life After Maxillectomy and Prosthetic Obturator Rehabilitation. J Oral Maxillofac Surg 2013;71:1471-8.

18. Beumer J, Curtis TA, Marunick MT. Maxillofacial Rehabilitation: Prosthodontic and Surgical Considerations. St. Louis; Ishiyaku Euro America: 1996. P. 225-84. 
19.Winkler S. Essentials of Complete Denture Prosthodontics. St. Louis; Ishiyaku Euroamerica: 2004. p. 403-16.

20.Wu YL, Schaaf NG: Comparison of Weight Reduction in Different Designs of Solid and Hollow Obturator Prostheses. J Prosthet Dent 1989;62:214-7.

21. Brown KE. Clinical Considerations Improving Obturator Treatment. J Prosthet Dent 1970; 24:461-6.

22. Desjardins RP: Obturator Prosthesis Design for Acquired Maxillary Defects. J Prosthet Dent 1978;39:424-35.

23. McAndrew KS, Rothenberger S, Minsley GE: An Innovative Investment Method for The Fabrication of A Closed Hollow Obturator Prosthesis. J Prosthet Dent 1998;80:129-32.

24. Phankosol P, Martin JW: Hollow Obturator with Removable Lid. J Prosthet Dent 1985;54:98-100.

25. Benington IC, Lappin C, Linden GJ. The Clinical Success and Periodontal Evaluation of Patients Rehabilitated with Light-cured Obturators. J Oral Rehabil 1996;23:135-8.

26. Kocacikli M, Yalug S, Yazicioglu H, Yilmaz C. Fabricating a Hollow Obturator with Visible Lightcured Resin System. J Prosthodont 2008;17:596-8.

27. Taicher S, Rosen AG, Arbree NS, Bergen SF, Levy M, Lepley JB. A Technique for Fabrication of Polydimethylsiloxane-acrylic Resin Obturators. J Prosthet Dent 1983;50:65-8.

28.Glossary of Prosthodontic Terms. J Prosthet Dent 2005;94:10-92.

29. Nidiffer TJ, Shipmon TH. The Hollow Bulb Obturator for Acquired Palatal Openings. J Prosthet Dent 1957;7:126-34.

30. Brown KE. Clinical Considerations Improving Obturator Treatment. J Prosthet Dent 1970;24: 461-6.

31.Parel SM, Drane JB. Prosthetic Support of The Visual Apparatus Following Maxillectomy and Orbital Floor Resection. J Prosthet Dent 1975;34: 329-33.

32. Beumer J, Curtis TA, Firtell DN. Maxillofacial Rehabilitation: Prosthodontic and Surgical Considerations. St Louis; CV Mosby: 1996. p. 188243.

33. Shimodaira K, Yoshida $H$, Yusa $H$, Kanazawa $T$. Palatal Augmentation Prosthesis with Alternative
Palatal Vaults for Speech and Swallowing: A Clinical Report. J Prosthet Dent 1998;80:1-3.

34. Aramany MA. Basic Principles of Obturator Design for Partially Edentulous Patients. Part II: Design Principles. J Prosthet Dent 1978;40:554-7.

35. Fischman B. The Use of Light-cured Material for Immediate Hollow Obturator Prosthesis. J Prosthet Dent 1989;61:215-6.

36. Paprocki GJ, Jacob RF, Kramer DC. Seal Integrity of Hollow Bulb Obturators. Int J Prosthodont 1990;3:457-62.

37. Riley C. Maxillofacial Prosthetic Rehabilitation of Postoperative Cancer Patients. J Prosthet Dent 1968;20:352-60.

38. Shimodaira K, Yoshida H, Mizukami M ,Funakubo T. Obturator Prosthesis Conforming to Movement of The Soft Palate: A Clinical Report. J Prosthet Dent 1994;71:547-51.

39. Özdemir H, Aladağ Lİ. Sonradan Kazanılmış Bir Maksiller Defektin Protetik Obturasyonu: Bir olgu sunumu. Atatürk Üniv Diş Hek Fak Derg 2011;4:122-7.

40.Bal BT, Yavuzyılmaz H. Yumuşak Astar Maddeleri. Atatürk Üniv Diş Hek Fak Derg 2006;1:53- 60.

41.Zarb GA. The Maxillary Resection and Its Prosthetic replacement. J Prosthet Dent 1967;18:268-81.

\author{
Yazışma Adresi \\ Dr. Öğr. Üyesi Hatice ÖzDEMİR, \\ Atatürk Üniversitesi Diş Hek. Fak. \\ Protetik Diş Tedavisi AD \\ TIf: 05453420080 \\ e-mail: dentist_hatice@hotmail.com
}

